\title{
Biología reproductiva de los tiburones de profundidad Aculeolanigra De Buen, 1959, y Centroscyllium nigrum Garman, 1899 (Chondrichthyes: Etmopteridae), centro-norte de Chile
}

\section{Reproductive biology of deep-sea sharks Aculeola nigra De Buen, 1959, and Centroscyllium nigrum Garman, 1899 (Chondrichthyes: Etmopteridae), from Central Northern Chile}

\author{
Cecilia Gatica ${ }^{1}$ \& Enzo Acuña ${ }^{1 *}$ \\ ${ }^{1}$ Departamento de Biología Marina. Universidad Católica del Norte. Casilla 117, Coquimbo, Chile. \\ *E-mail: eacuna@ucn.cl
}

\begin{abstract}
RESUMEN
Se describen aspectos de la reproducción de los tiburones de profundidad Aculeola nigra y Centroscyllium nigrum, capturados como fauna acompañante de la pesquería de crustáceos. Se examinó un total de 269 especímenes de $A$. nigra y 284 especímenes de C. nigrum obtenidos en la zona centro-norte de Chile, durante los meses de junio a diciembre del 2006, a los que se les evaluó su condición reproductiva, se caracterizó sus gónadas, se obtuvieron el IGS, IHS y la talla de madurez sexual $\left(\mathrm{L}_{50 \%}\right)$. Los resultados mostraron que el IGS es máximo entre agosto y septiembre en $A$. nigra y entre septiembre y noviembre en $C$. nigrum, indicando que probablemente esa sea su época de máxima reproducción. Se obtuvo la talla de madurez sexual para ambas especies; $38 \mathrm{~cm}$ longitud total (LT) para machos y $39 \mathrm{~cm}$ LT en hembras de $A$. nigra; y $32 \mathrm{~cm} \mathrm{LT}$ para machos y hembras de C. nigrum. Se registró una fecundidad de $5-17$ embriones en $A$. nigra y de $4-15$ embriones en $C$. nigrum, con tallas de nacimiento de $16,7 \mathrm{~cm} \mathrm{LT}$ para $A$. nigra y $15,7 \mathrm{~cm}$ LT para $C$. nigrum. Con los resultados histológicos se concluyó que los testículos de ambas especies se clasifican como de tipo diamétrico y los ovarios como del tipo externo o carcharhínido.
\end{abstract}

Palabras Clave: Estructura microscópica, reproducción, talla de madurez sexual, viviparía lecitotrófica.

\begin{abstract}
The reproductive biology of the deep-sea sharks Aculeola nigra and Centroscyllium nigrum, caught as by-catch in the crustacean fishery, is described. A total of 269 specimens of $A$. nigra and 284 specimens of $C$. nigrum obtained in centralnorthern Chile between June and December 2006, were examined. Their reproductive condition was assessed considering the characterization of the gonads, the GSI and HSI indices and their size at maturity $\left(\mathrm{L}_{50 \%}\right)$. The results showed that the GSI is highest between August and September in A. nigra and between September and November in C. nigrum, which probably indicates their breeding season. The sexual maturity for both species was determined at $38 \mathrm{~cm}$ total length (TL) for males and $39 \mathrm{~cm}$ TL in females $A$. nigra and $32 \mathrm{~cm}$ TL for males and females of $C$. nigrum. Pregnant $A$. nigra showed a fecundity of 5 - 17 embryos while $C$. nigrum had a fecundity of $4-15$ embryos, with birth sizes of $16.7 \mathrm{~cm}$ TL for $A$. nigra and $15.7 \mathrm{~cm}$ TL for $C$. nigrum. The histological results showed that the testes of both species are diametric and the ovaries external or carcharhinid.
\end{abstract}

KEYwORDS: Microscopic structure, reproduction, size at sexual maturity, lecithotrophic vivipary.

\section{INTRODUCCIÓN}

Los peces cartilaginosos presentan bajo crecimiento, edad de madurez sexual tardía y baja fecundidad, sobre todo aquellas especies adaptadas a la vida en aguas profundas (Kyne \& Simpfendorfer 2007), además están adaptados a vivir en un ecosistema con cambios ambientales infrecuentes, por lo tanto son vulnerables tanto a la explotación como a las alteraciones de su hábitat como todos los peces de profundidad (Large \& Bergstad 2003). 
Los miembros de la familia Etmopteridae (Chondrichthyes: Squaliformes) Aculeola nigra De Buen, 1959 y Centroscyllium nigrum Garman, 1899 son tiburones frecuentemente capturados por las flotas arrastreras de la pesquería de crustáceos que capturan langostino colorado Pleuroncodes monodon H. Milne Edwards, 1837, langostino amarillo Cervimunida johni Porter, 1903 y camarón nailon Heterocarpus reedi Bahamonde, 1955, en la costa centronorte de Chile (Acuña et al. 2005). A. nigra se distribuye en el Pacífico oriental desde Perú a Chile central (Compagno 1984; Sielfeld \& Vargas 1996) y C. nigrum ha sido encontrado en el Pacífico central, Pacífico oriental, surmeridional, California, Panamá (Compagno 1984), Chile (Sielfeld \& Vargas 1996; Acuña et al. 2005), y más recientemente también ha sido registrado en Colombia (Rubio et al. 2005).

En general existen pocos antecedentes sobre la biología reproductiva de los tiburones de profundidad $A$. nigra y $C$. nigrum, sólo hay registros que su modo de reproducción es el viviparismo lecitotrófico y de la talla de madurez sexual de $A$. nigra (Compagno 1984). Sin embargo, no se dispone en la actualidad de información sobre sus estructuras reproductivas, ciclo reproductivo, fecundidad, talla de nacimiento y revisión de las tallas de madurez sexual de ambas especies.

Con respecto a la parte microscópica de las gónadas de los condrictios, Pratt (1988) analiza la estructura de las gónadas de los squalomorfos Centrophorus granulosus y Squalus acanthias y de los scyliorhínidos Scyliorhinus canicula y $S$. retifer y entrega información general definiendo tres tipos de testículos según su estructura y desarrollo: diamétrico, radial y compuesto, y distingue dos tipos: interno y externo.

El objetivo de este trabajo es estudiar la biología reproductiva de los etmoptéridos de profundidad $A$. nigra y $C$. nigrum, en aspectos como describir las características morfológicas externas e internas del aparato reproductor tanto en machos y hembras, incluyendo un análisis histológico de las gónadas; ciclo reproductivo; fecundidad, tallas de nacimiento y reevaluar sus tallas de madurez sexual.

\section{MATERIALES Y MÉTODOS}

Las muestras provienen de la fauna acompañante de las capturas realizadas entre junio y diciembre de 2006, en el marco de la ejecución de los proyectos FIP N $N^{\circ} 2006-04$ Evaluación directa del langostino colorado y langostino amarillo entre la II y VIII Región, año 2006 (Acuña et al. 2007a) y FIP N ${ }^{\circ}$ 2006-11 Evaluación directa del camarón nailon entre la II y VIII Región, año 2006 (Acuña et al. 2007b). Los ejemplares fueron obtenidos entre los $24^{\circ} 12^{\prime} 280^{\prime \prime} \mathrm{S}$ y $34^{\circ} 02^{\prime} 562^{\prime} \mathrm{S}$ en la zona centro-norte de
Chile entre los 276 y $623 \mathrm{~m}$ de profundidad, mediante la utilización de redes de arrastre.

Los ejemplares se identificaron a nivel de especie utilizando los trabajos de Compagno (1984) y Lamilla \& Bustamante (2005). Se analizaron 269 ejemplares de Aculeola nigra (142 hembras y 127 machos) y 284 ejemplares de Centroscyllium nigrum (189 hembras y 95 machos), a los cuales se les determinó el sexo por la presencia de clasper en los machos y se midió su longitud total (LT, $0,1 \mathrm{~cm}$ ) y peso total (PT, 0,1 g). Se analizó la relación talla-peso de las dos especies para sexos combinados.

En cada ejemplar se realizó una disección desde la cloaca a la región pectoral para extraer el hígado y el aparato reproductor, del cual los testículos y ovarios se fijaron en formalina al $10 \%$ con agua de mar por $24 \mathrm{~h}$ y luego fueron sometidos a tres cambios de alcohol $30^{\circ}, 50^{\circ}$ y $70^{\circ}$ para su análisis histológico. El hígado y el sistema reproductor de cada ejemplar fue pesado en una balanza semianalítica \pm 0,1 g para determinar tanto el índice hepatosomático (IHS) como el índice gonadosomático (IGS).

El IHS se calculó de acuerdo a Watson y Smale (1998)

$$
I H S=(p h / p t) * 100
$$

donde $p h$ es el peso del hígado y $p t$ es el peso total del individuo.

El IGS se calculó de acuerdo a Watson y Smale (1998)

$$
I G S=(p g / p t) * 100
$$

donde $p g$ es el peso total de la gónada y $p t$ el peso total del individuo. Luego de obtenidos los resultados para ambos índices se calculó un promedio y su desviación estándar.

La talla de primera madurez sexual (TPMS) se calculó empleando la $\mathrm{LT}_{50}$, cuyo valor corresponde al tamaño promedio cuando el $50 \%$ de la población estudiada alcanza su madurez sexual, examinando la fracción de machos y hembras maduras en función del modelo logístico que se representa con la siguiente ecuación (Barone et al. 2007):

$$
P L=1 / 1+\exp ^{(a+b L)}
$$

donde $P L$ es la proporción de individuos maduros al rango de talla L; a y b parámetros a estimar con la ecuación logística y LT es la longitud total. La talla al 50\% de madurez se determinó con $\mathrm{L}_{50 \%}=\mathrm{a} / \mathrm{b}$ por sustitución de $\mathrm{PL}=0,5$ en la ecuación. Los parámetros fueron estimados mediante 
máxima verosimilitud, considerando la distribución binomial del error.

Los ejemplares analizados de ambos sexos se clasificaron de acuerdo a los estados de madurez macroscópicos propuestos por Stehmann (2002) (Tabla 1), según las características de su anatomía reproductiva. En el caso de los machos además, se midió el largo total externo e interno del clasper de acuerdo a Compagno (1984) y los testículos en su largo total $(0,1 \mathrm{~cm})$. En las hembras se contó el número y se midió el diámetro de los ovocitos $(0,1 \mathrm{~cm})$ y se cuantificó la presencia de embriones, los que a su vez fueron medidos y pesados. Se estimó la talla de nacimiento, como el promedio entre la longitud total máxima embrionaria y la longitud total menor de los tiburones capturados de acuerdo a lo sugerido por Moreno et al. (2010). Se estableció una relación entre la longitud total de la hembra y el número total de embriones por camada, y entre la longitud total del embrión y el diámetro de su saco vitelino.

Se obtuvieron trozos de aproximadamente $5 \mathrm{~mm}$ de testículo y ovario mediante cortes transversales en la sección central de cada uno, los que fueron deshidratados con un procesador de tejido automático, para posteriormente ser incluidas en parafina Paraplast. El bloque obtenido fue seccionado en cortes de $5 \mu \mathrm{m}$ de espesor con un micrótomo y teñido con hematoxilina-eosina de Harris.

Los cortes histológicos se observaron con un microscopio fotónico. En los testículos se identificó la posición de la zona germinativa y la disposición de desarrollo de los folículos seminíferos. Los cortes histológicos de ovario se clasificaron según la disposición de los ovocitos. Se utilizó la clasificación de Pratt (1979) para caracterizar los cortes histológicos en machos y hembras.

TABLA 1. Estados de madurez macroscópicos empleados para el estudio reproductivo basados en Stehmann (2002).

TABLE 1. Macroscopic maturity stages used for the reproductive study based in Stehmann (2002).

\begin{tabular}{|c|c|c|c|}
\hline Sexo & Descripción & Ovario & Útero \\
\hline \multirow{9}{*}{ Hembras } & \multicolumn{3}{|c|}{ Estados Ováricos } \\
\hline & Inmaduro (A) & Granulado y de consistencia acuosa. & $\begin{array}{l}\text { Delgado con forma de hilos pegado a la } \\
\text { cavidad abdominal. }\end{array}$ \\
\hline & En maduración (B) & $\begin{array}{l}\text { Ovocitos diferenciados en varios } \\
\text { tamaños. }\end{array}$ & Ancho en región posterior. \\
\hline & Madura (C) & $\begin{array}{l}\text { Redondeado de gran tamaño, } \\
\text { ovocitos fácil de contar. }\end{array}$ & Alargado y ancho \\
\hline & \multicolumn{3}{|c|}{ Estados Uterinos } \\
\hline & Activo (D) & Redondeado & Lleno de vitelo \\
\hline & Avanzado (E) & Redondeado & $\begin{array}{l}\text { Segmentado con embriones con saco } \\
\text { vitelino. }\end{array}$ \\
\hline & Expulsante $(\mathrm{F})$ & Redondeado, de distintos tamaños. & $\begin{array}{l}\text { Presenta embriones formados, con aspecto } \\
\text { adulto. }\end{array}$ \\
\hline & PostParto (G) & Redondeado en forma de gránulos. & Vacío y de gran ancho \\
\hline \multirow{5}{*}{ Machos } & & Claspers & Conductos deferentes \\
\hline & Inmaduro (A) & $\begin{array}{l}\text { Pequeño, largo no sobrepasa la aleta } \\
\text { pélvica y flexible. }\end{array}$ & Con forma de hilos. \\
\hline & En maduración (B) & $\begin{array}{l}\text { Largo sobrepasa la aleta pélvica y } \\
\text { flexible. }\end{array}$ & Con pequeñas ondulaciones. \\
\hline & Maduro (C) & $\begin{array}{l}\text { Largo sobrepasa la aleta pélvica y } \\
\text { calcificado. }\end{array}$ & Completamente ondulados o espiralados. \\
\hline & Activo (D) & $\begin{array}{l}\text { Largo sobrepasa la aleta pélvica, } \\
\text { dilatado, vacío. }\end{array}$ & Con presencia de flujo espermático. \\
\hline
\end{tabular}


Las fases de la espermatogénesis se clasificaron de acuerdo a Maruska et al. (1996) (Tabla 2) y se utilizó el programa AxioVision LE Rel. 4,5 para el recuento de cada fase espermatogénica y para determinar la proporción o porcentaje de la gónada que ocupa cada una de éstas, con lo que se determinó la madurez gonádica. Con un test MANOVA se determinó si existían diferencias entre los porcentajes de cada fase espermatogénica en cada estado de madurez macroscópico. En las hembras se midió cada ovocito presente en el corte y se clasificaron en previtelogénicos, vitelogénicos y maduros según características que indican su estado de maduración, como la presencia de vitelo y su tamaño (Tresierra et al. 2002).

TABLA 2. Fases histológicas del desarrollo testicular. Modificado de Maruska et al. (1996).

TABLE 2. Histological stages of testicular development. Modified from Maruska et al. (1996)

\begin{tabular}{|c|c|}
\hline Fase & Descripción \\
\hline I & $\begin{array}{l}\text { Espermatogonias presentes en la periferia que corresponde a la zona primaria } \\
\text { o germinal, son las células de mayor tamaño y presentan núcleo esférico con } \\
\text { cromatina condensada. }\end{array}$ \\
\hline II & $\begin{array}{l}\text { Espermatocito primario, células situadas en la zona intermedia de menor tamaño } \\
\text { que las espermatogonias. }\end{array}$ \\
\hline III & $\begin{array}{l}\text { Espermatocito secundario, células situadas en la zona intermedia, tienen forma } \\
\text { esférica. }\end{array}$ \\
\hline IV & $\begin{array}{l}\text { Espermátida 1, células más pequeñas que las anteriores, son de forma esférica con } \\
\text { núcleo elíptico. }\end{array}$ \\
\hline $\mathrm{V}$ & $\begin{array}{l}\text { Espermátida 2, son de forma alargada se encuentran después de las espermátidas } \\
1 \text {. }\end{array}$ \\
\hline VI & $\begin{array}{l}\text { Esperma inmaduro, espermátida en proceso de espermiogénesis con diferenciación } \\
\text { de cabeza espermática, pieza media y cola, pero se encuentra muy desorganizado. }\end{array}$ \\
\hline VII & $\begin{array}{l}\text { Esperma maduro, esperma con su proceso de maduración completo, están } \\
\text { organizados en paquetes asociados a células de Sertoli en la región apical, tienen la } \\
\text { cabeza con forma de espiral orientada hacia la periferia. }\end{array}$ \\
\hline VIII & $\begin{array}{l}\text { Zona degenerativa, extremo opuesto a la zona primaria o germinal y contiene } \\
\text { espermatocistos vacíos por rompimiento de espermatogonia. }\end{array}$ \\
\hline
\end{tabular}

\section{RESULTADOS}

Se registró ejemplares hembras de Aculeola nigra entre 16,5 a $67 \mathrm{~cm}$ LT con un rango de peso de 20,3 a $1.480 \mathrm{~g} \mathrm{y}$ ejemplares machos en un rango entre $17,5-53,9 \mathrm{~cm}$ y PT de 23 a 792,7 g (Fig. 1a).

En Centroscyllium nigrum las hembras presentaron un rango de tallas entre 15 - 51,4 cm LT y de PT entre los 9,6 a 841,5 $\mathrm{g}$, los machos presentaron un rango entre 23,4 - 45,7 cm LT y de PT entre 10 a 357,8 g (Fig. 1b).
En $A$. nigra se encontró 22 hembras con embriones en el útero en los meses de septiembre $(n=9)$, octubre $(n=10)$ y noviembre $(n=3)$, que corresponden al $15 \%$ del total de hembras examinadas, las que presentaron un total de 235 embriones. Se encontró hembras con embriones a partir de la talla de $40 \mathrm{~cm} \mathrm{LT}$, la fecundidad fue de 5 - 19 embriones, con un promedio de $10,9 \pm 3,52$ por hembra. En el útero derecho se encontró de 3 a 9 embriones con un promedio de $5,4 \pm 1,6$ y en el útero izquierdo 2 - 10 embriones, con un promedio de 5,7 $\pm 2,2$. El rango de tallas de los embriones encontrados fue de 2,3 a $17 \mathrm{~cm}$ LT, mientras que la talla 
promedio de nacimiento estimada fue de $16,75 \mathrm{~cm} \mathrm{LT}$.

En C. nigrum se encontró 30 hembras con embriones en el útero en los meses de septiembre $(n=1)$, octubre $(n=13)$ y noviembre $(n=16)$, que corresponden al $16 \%$ del total de hembras examinadas, las que presentaron un total de 252 embriones. Se registró hembras con embriones a partir de los 33,2 cm LT, la fecundidad fue de 4 - 15 embriones con un promedio de $8,4 \pm 2,84$ de embriones por hembra. En el útero derecho se encontró de 2 - 7 embriones con un promedio 4,2 $\pm 1,4 \mathrm{y}$ en el útero izquierdo se registró de 2 - 6 embriones con un promedio de 4,1 $\pm 1,5$. El rango de talla de los embriones fue de $2,4 \mathrm{~cm}$ a $16,5 \mathrm{~cm}$ LT. La talla de nacimiento estimada fue de $15,75 \mathrm{~cm} \mathrm{LT}$.

La relación entre la longitud total de la hembra y el número total de embriones por camada, resultó en una correlación positiva, aunque con coeficientes de determinación medios, tanto en $A$. nigra $\left(\mathrm{P}=0,001, \mathrm{r}^{2}=0,45\right)$ (Fig. 2a) como en $C$. nigrum $\left(\mathrm{P}=0,005, \mathrm{r}^{2}=0,59\right)$ (Fig. 2b).
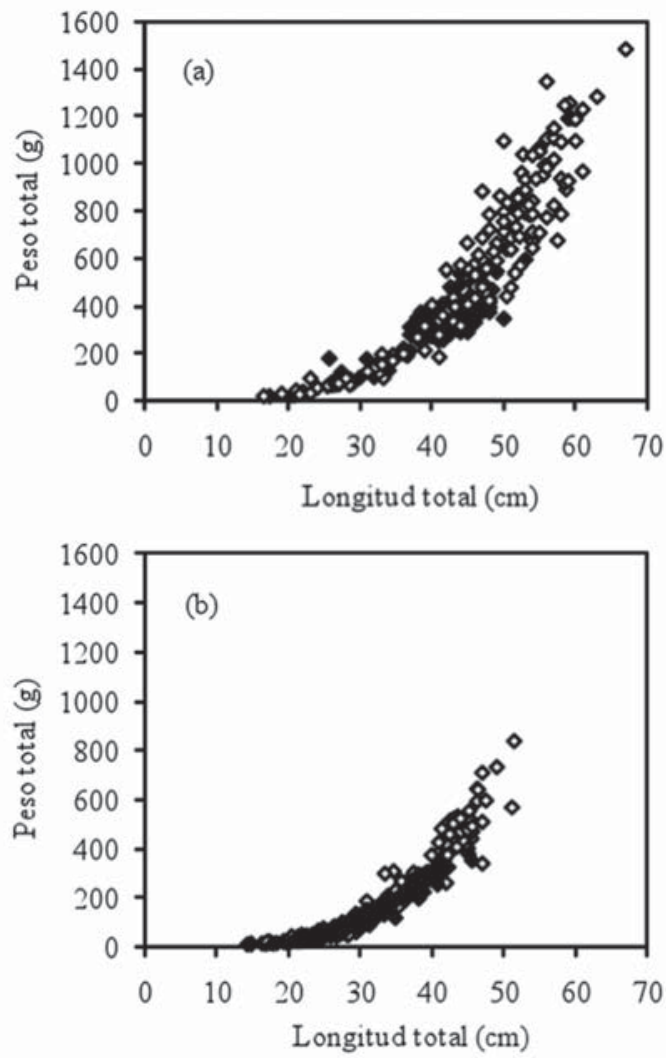

Figura 1. Relación Longitud Total (cm) - Peso Total (g). (a) $A$. nigra, (b) C. nigrum. Machos $\diamond$ Hembras.

FIgURE 1. Total Length $(\mathrm{cm})$ - Total Weight (g) relationship for (a) A. nigra, (b) C. nigrum. $\diamond$ Males $\diamond$ Females.
La talla del saco vitelino se correlacionó inversamente con la longitud total del embrión en ambos tiburones; en $A$. nigra $(\mathrm{P}=0,000, \mathrm{r}=0,91)$ (Fig. $3 \mathrm{a})$ se registró que el saco vitelino fue totalmente absorbido por los embriones a partir de los $13,5 \mathrm{~cm}$ LT y a partir de los $14 \mathrm{~cm}$ LT en $C$. nigrum $(\mathrm{P}=0,000, \mathrm{r}=0,78)$ (Fig. 3b).

\section{ÍNDICE GONADOSOMÁTICO E ÍNDICE HEPATOSOMÁTICO}

En A. nigra, durante los meses de junio y julio se encontró una proporción mayor de hembras inmaduras, lo que coincide con los valores mínimos del IGS, aumentando en agosto la importancia de hembras maduras (Fig. 4a). Durante el periodo de septiembre a octubre, se encontró el porcentaje mayor de hembras con embriones mientras que en noviembre y diciembre aparecen hembras en todos los estados de madurez y aumenta la proporción de hembras en postparto. El IHS presentó el valor máximo en julio ( $\mathrm{x}=19,06 \pm 2,74)$ (Fig. 4a), probablemente debido a la acumulación de reservas para etapas posteriores de maduración sexual.
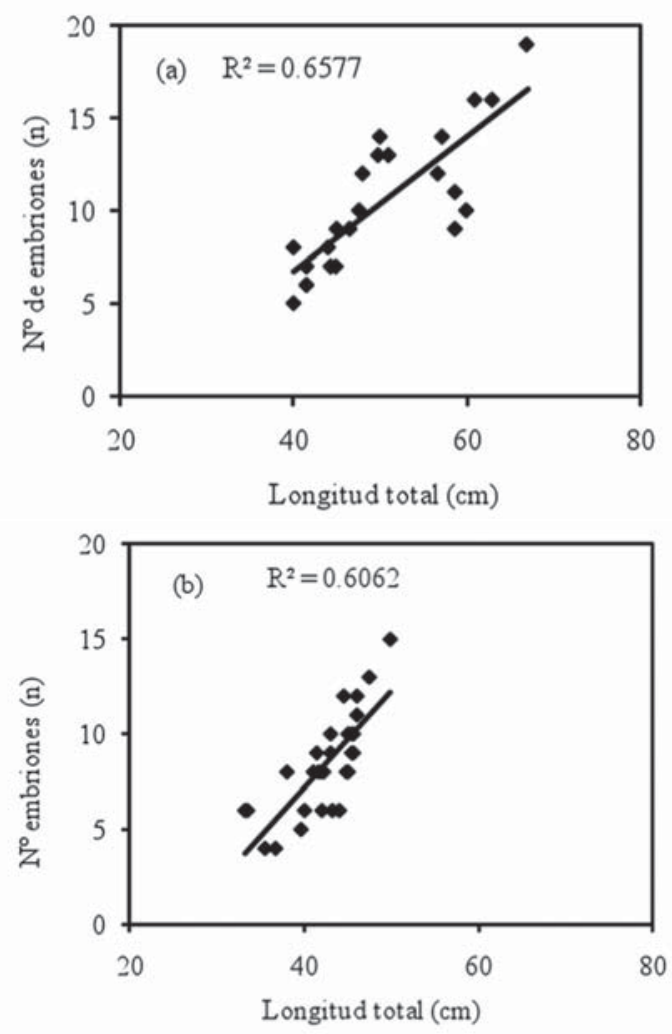

FIgURA 2. Relación Longitud Total $(\mathrm{cm})$ de la hembra y número de embriones por camada. (a) A. nigra, (b) C. nigrum.

FIGURE 2. Relationship between female Total Length (cm) and number of embryos per litter. (a) A. nigra, (b) C. nigrum. 
En C. nigrum, al igual que en A. nigra, durante los meses de junio y julio se encontró una proporción mayor de hembras inmaduras, lo que coincide con los valores mínimos del IGS, sin embargo, a diferencia de A. nigra, el máximo del IGS ocurre en noviembre (Fig. 4b), siendo importante considerar que durante el período de octubre y noviembre existe un mayor número de hembras con embriones. Las hembras de $C$. nigrum presentan su valor máximo del IHS en diciembre ( $\mathrm{x}=$ $24,75 \pm 2,82$ ) (Fig. 4b), lo que podría significar acumulación de reservas durante la recuperación postparto.

En los machos de A. nigra (Fig. 4c) en el mes de agosto se observa el valor máximo del IGS $(x=1,95 \pm 0,21)$, con la presencia de mayor número de machos maduros, lo que indica una mayor producción de esperma para la época reproductiva. En los meses posteriores se observa un descenso de estos valores que vuelven a aumentar en noviembre $(0,72$ $\pm 0,37)$. En los machos de $A$. nigra el valor mayor del IHS se presenta en octubre ( $x=20,7 \pm 1,78)$ (Fig. $4 c)$.

En los machos de C. nigrum (Fig. 4d) al igual que A. nigra, el IGS presenta valores máximos en el mes de agosto y luego en noviembre, los que contrastan con los valores bajos del IHS.
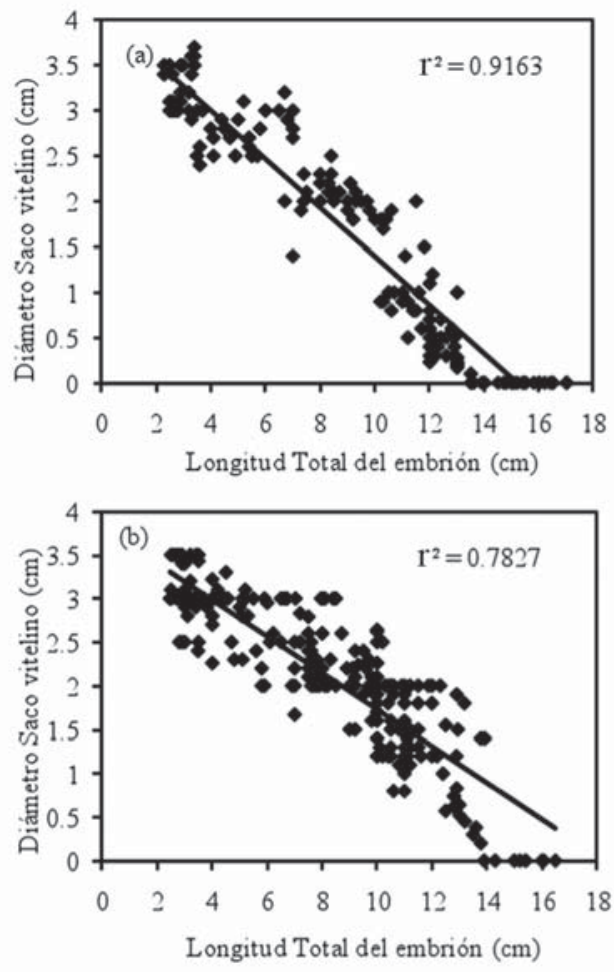

FIGURA 3. Relación entre la longitud total del embrión y el diámetro de su saco vitelino. (a) A. nigra, (b) C. nigrum.

FIGURE 3. Relationship between total length of the embryo and yolk sac diameter. (a) A. nigra, (b) C. nigrum.
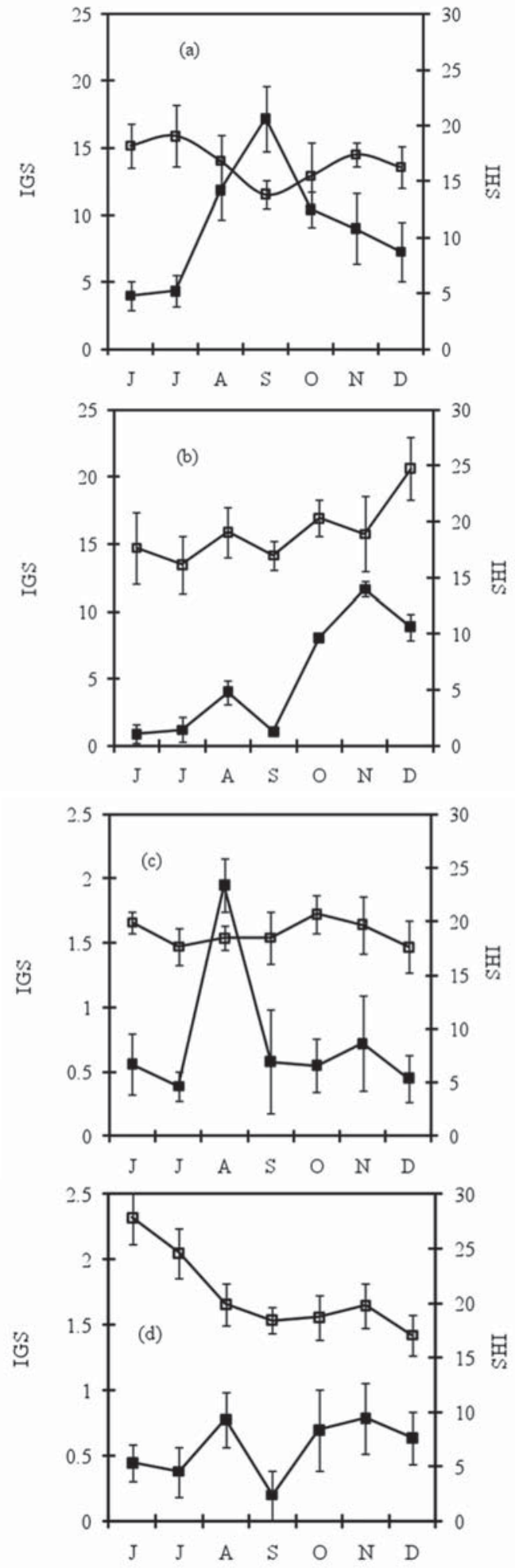

FIgURA 4. Índice Gonadosomático e Índice Hepatosomático de hembras de (a) A. nigra y (b) C. nigrum y machos de (c) A. nigra y (d) C. nigrum. IGS, $\square$ IHS. Los datos se expresan como un promedio \pm desviación estándar.

Figure 4. Gonadosomatic Index and Hepatosomatic Index of females (a) A. nigra, (b) C. nigrum and males (c) A. nigra, (d) $C$. nigrum. $\square$ GSI, $\square$ HSI. Data is a mean \pm standard deviation. 

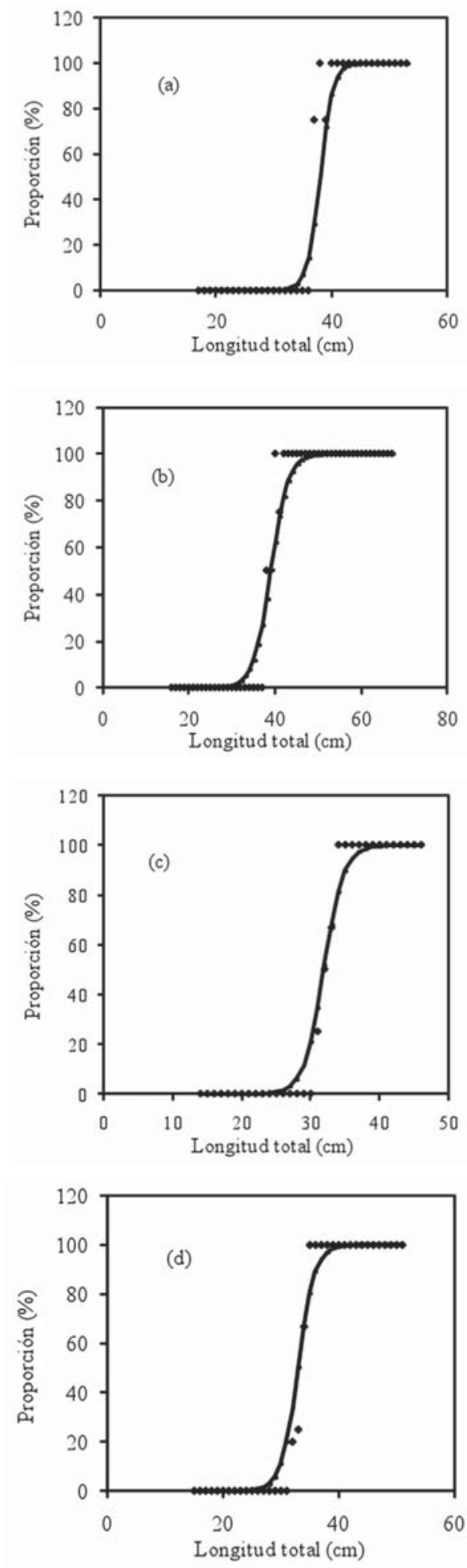

Figura 5. Proporción (\%) de especímenes maduros en cada Longitud Total. Representado por una curva logística. (a) A. nigra, (b) C. nigrum. hembras $\diamond$ machos.

Figure 5. Proportion (\%) of mature specimens at each Total Length. Represented by a logistic curve. (a) A. nigra, (b) C. nigrum. females; $\diamond$ males.
TALLA DE PRIMERA MADUREZ $\mathrm{LT}_{50}$ El valor de $\mathrm{LT}_{50}$ en $A$. nigra presentó valores de $38 \mathrm{~cm} \mathrm{LT}$ para machos $(\mathrm{n}=127)$ y $39 \mathrm{~cm}$ LT para las hembras $(\mathrm{n}=142)$ (Fig. 5a). En C. nigrum los valores corresponden a $32 \mathrm{~cm} \mathrm{LT}$ para machos $(n=95)$ y hembras $(n=189)$, respectivamente (Fig. 5b).

\section{ANATOMÍA REPRODUCTIVA EN MACHOS}

En los ejemplares examinados de $A$. nigra se observa que la calcificación del clasper ocurre a los 35,6 cm LT (Fig. 6a). La longitud total interna del clasper (LTIC) alcanza un tamaño de $5 \mathrm{~cm}$ y la longitud total externa del clasper (LTEC) de $2 \mathrm{~cm}$ de longitud máxima.

En C. nigrum, la calcificación del clasper ocurre a los 32,5 cm LT de los ejemplares examinados (Fig. 6b), mientras que la LTIC alcanza un tamaño de $4 \mathrm{~cm}$ y la LTEC de $2,5 \mathrm{~cm}$.
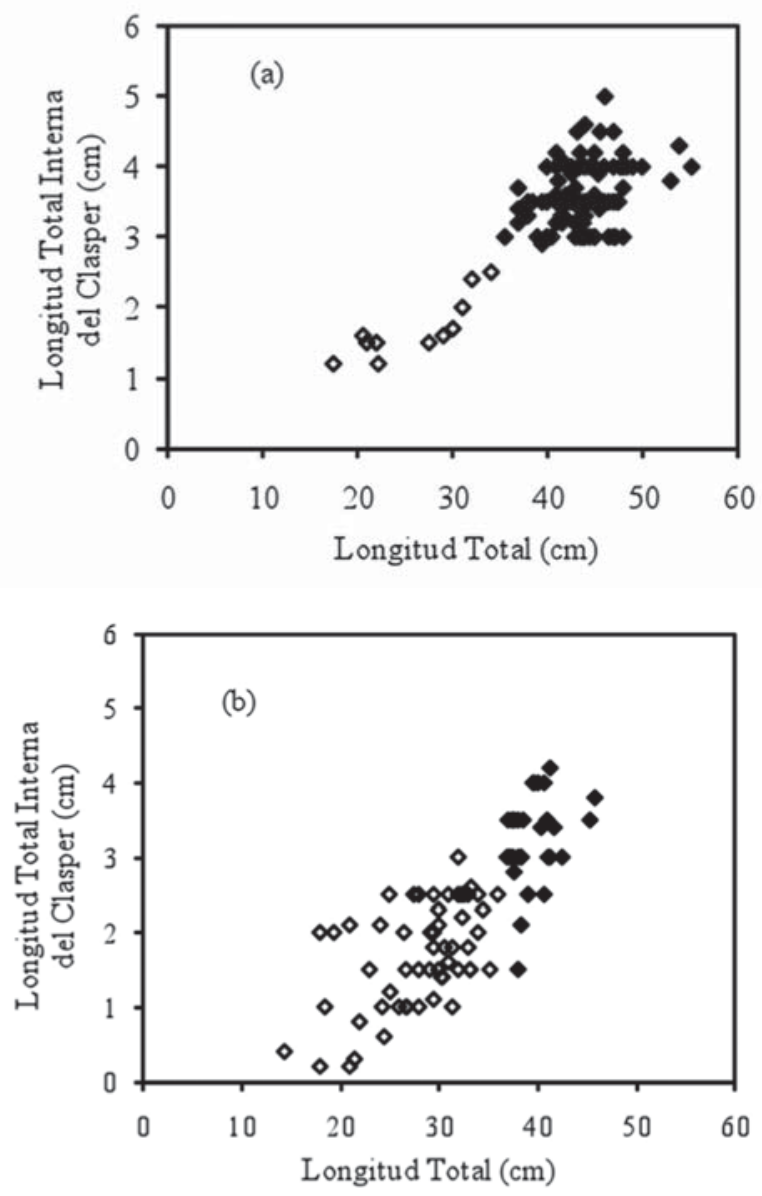

FIgURA 6. Relación Longitud Total y Longitud Total Interna del Clasper en (a) A. nigra, (b) C. nigrum. $\bigcirc$ no calcificado; • calcificado.

Figure 6. Relationship between Total Length and Clasper Internal Total Length relationship in (a) A. nigra, (b) C. nigrum. $\bigcirc$ non calcified; • calcified. 


\section{Aculeola nigra}

El estado A o inmaduro (Tabla 1) se observó en ejemplares con un rango de talla entre 17,5 y 22,2 cm LT y se caracterizó por presentar un par de testículos de forma alargada, coloración rojiza y un tamaño promedio de $1,5 \pm 0,53 \mathrm{~cm}$, totalmente adheridos a la cavidad abdominal en la región anterior. El epidídimo y los conductos deferentes no están diferenciados entre sí, sólo se observan en forma de hilos de color blanquecino que recorren la cavidad abdominal desde la zona superior de los testículos hasta la cloaca. El clasper tiene un tamaño total promedio de $1,4 \pm 0,17 \mathrm{~cm}$ LTIC que no sobrepasa la aleta pélvica, un ancho de $0,4 \pm 0,12 \mathrm{~cm}$ y no está calcificado.

El estado B o en maduración (Tabla 1, Fig. 7a) se observó en los ejemplares con tallas entre 25,8 y $34 \mathrm{~cm} \mathrm{LT}$, y se caracteriza por presentar testículos de forma tubular, de coloración rojiza, alargados, alcanzando una longitud promedio de 2,7 $\pm 0,69 \mathrm{~cm}$, más libres, sólo unidos a la cavidad abdominal por el tejido mesorchium en su región lateral. El epidídimo y los conductos deferentes se observan con pequeñas ondulaciones, son delgados y de coloración blanquecina. El clasper tiene un tamaño total promedio de $2,1 \pm 0,37 \mathrm{~cm}$ y un ancho de $0,47 \pm 0,07 \mathrm{~cm}$, su longitud total sobrepasa la aleta pélvica, pero continúa no calcificado.

El estado C o maduro (Tabla 1, Fig. 7b) se observó en los ejemplares con tallas entre 35 y $42,6 \mathrm{~cm} \mathrm{LT}$, cuyos testículos son de forma lobulada, alargados con un tamaño de 3,7 $\pm 1,05 \mathrm{~cm}$ y de coloración blanquecina; la cabeza del epidídimo es diferenciable en la región superior donde se ubican los testículos, el cuerpo del mismo se encuentra totalmente enrollado y es distinto de los conductos deferentes de forma ondulada. El clasper tiene un LTIC promedio de 3,1 $\pm 0,46 \mathrm{~cm}$, un ancho de 0,48 $\pm 0,09 \mathrm{~cm}$ y se encuentra totalmente calcificado.

En el estado D o activo (Tabla 1), el rango de talla fue de 39,5 a 53,9 cm LT y los ejemplares se caracterizaron por poseer los testículos de forma lobulada y de un tamaño promedio de 4,93 $\pm 0,97 \mathrm{~cm}$. En los conductos deferentes hay flujo de esperma, el que se observó además en la región cloacal. El clasper presenta una LTIC promedio de 3,5 $\pm 0,49 \mathrm{~cm}$ y un ancho de $0,56 \pm 0,14 \mathrm{~cm}$.

\section{Centroscyllium nigrum}

El estado A o inmaduro (Tabla 1, Fig. 7c) se observó en ejemplares con un rango de talla entre $18 \mathrm{~cm}$ y $29 \mathrm{~cm} \mathrm{LT}$; en los individuos de 18 a $22 \mathrm{~cm}$ LT los testículos son poco visibles debido a su escaso desarrollo, sólo se observan los conductos y el epidídimo en forma de hilos delgados. En los individuos de 23 a $29 \mathrm{~cm}$ LT los testículos aparecen de forma delgada y tubular, y presentan una longitud total promedio de $2,48 \pm 0,78 \mathrm{~cm}$. El clasper tiene un LTIC promedio de
$1,59 \pm 0,71 \mathrm{~cm}$, que no sobrepasa la aleta pélvica, un ancho de $0,32 \mathrm{~cm} \pm 0,11$ y no está calcificado.

El estado B o en maduración (Tabla 1) se observó en ejemplares de tallas entre 29,3 y 31,1 cm LT, los que se caracterizaron por presentar testículos de forma tubular, de coloración blanquecina y alargados, con una longitud promedio de 2,47 $\pm 0,4 \mathrm{~cm}$. El epidídimo y los conductos deferentes se observan con pequeñas ondulaciones, son delgados y de coloración blanquecina. El clasper tiene un LTIC promedio de $1,96 \pm 0,46 \mathrm{~cm}$ y un ancho de $0,42 \pm$ $0,08 \mathrm{~cm}$, su longitud total sobrepasa la aleta pélvica, pero continúa sin calcificar.

El estado C o maduro (Tabla 1, Fig. 7d) se observó en ejemplares de tallas entre 32 y 40,6 cm LT. Los testículos tienen forma espiralada o enroscada, con un tamaño de 3 $\pm 0,9 \mathrm{~cm}$ y de coloración blanquecina, sujetos a la cavidad abdominal ventral por el tejido mesorchium, claramente distinguible de los testículos; el epidídimo se encuentra totalmente enrollado y los conductos deferentes tienen forma ondulada. El clasper tiene un LTIC promedio de $2,71 \pm 0,71 \mathrm{~cm}$, un ancho de $0,42 \pm 0,08 \mathrm{~cm}$ y se encuentra totalmente calcificado.

El estado D o activo (Tabla 1) se observó en ejemplares de talla entre $36 \mathrm{~cm}$ y $42,4 \mathrm{~cm} \mathrm{LT}$, se caracteriza por presentar testículos de un tamaño promedio de $5,13 \mathrm{~cm}$ $\pm 0,72$, con la misma estructura del estado anterior y por tener los conductos deferentes con flujo de esperma al presionar el seno urogenital. El clasper presenta una LTIC promedio de 3,34 $\mathrm{cm} \pm 0,43 \mathrm{y}$ un ancho de $0,48 \pm$ $0,08 \mathrm{~cm}$.

\section{ESTRUCTURA MICROSCÓPICA DEL TESTÍCULO}

En ambos tiburones, el testículo presenta la zona germinativa en un extremo del lóbulo y las ámpulas se desarrollan diamétricamente a lo largo de la gónada, situándose la zona madura en el extremo opuesto de la germinativa (Fig. 8). Cada ámpula posee células que se encuentran en el mismo estado espermatogénico. El testículo está rodeado por tejido conjuntivo y en el corte se observa el tejido mesorchium, que lo une a la cavidad abdominal. En la gónada se disponen primero las espermatogonias que presentan un tamaño promedio de $25,4 \pm 1,2 \mu \mathrm{m}$, poseen forma esférica y están rodeadas por células de Sertoli en la zona germinativa, luego están los espermatocistos conteniendo espermatocitos primarios de un tamaño promedio de $15 \pm 1,7 \mu \mathrm{m}$ y los espermatocitos secundarios de un tamaño de $13 \pm 0,7$ $\mu \mathrm{m}$. Después están las espermátidas que se desarrollan durante la espermiogénesis y de las cuales se diferencian tres tipos: aquéllas en estado 1 que son de forma elíptica y de menor tamaño que los espermatocitos secundarios, 
aquéllas en estado 2 que se encuentran más condensadas en el interior de la ámpula y son alargadas, y las en etapa 3 o también denominadas esperma inmaduro, se ven todas unidas. Los espermatozoides tienen la cabeza eosinófila de forma espiralada, una pieza media distinguible y un flagelo delgado y basófilo y se encuentran rodeados por células de Sertoli de forma esférica en la región de los bordes de cada ámpula. En la zona degenerativa las ámpulas se encuentran vacías por la evacuación de los espermatozoides.

\section{FASES ESPERMATOGÉNICAS}

En A. nigra el estado A de la gónada está compuesto de $28 \%$ de espermatogonias, $61 \%$ de espermatocitos primarios y secundarios y 1,9\% de espermátidas. En el estado B hay un aumento de las espermátidas a un $51 \%$ y se observa un $15 \%$ de espermatozoides. En los estados C y D los espermatozoides representan el mayor porcentaje con 28 y $31 \%$, respectivamente, y en la zona degenerativa aparecen espermatocitos vacíos que corresponden al 5 y $8 \%$, respectivamente (Fig. 9a). Los promedios de cada proporción de los estados espermatogénicos no son significativamente diferentes entre los estados de madurez macroscópicos $(\mathrm{P}>0,05)$.
En C. nigrum, en el estado A, el mayor porcentaje de la gónada estuvo representado por espermatocitos primarios y secundarios con un $68 \%$, y espermátidas en estado $1 \mathrm{y}$ 2 con un 4\%. En el estado B se observa mayor cantidad de espermátidas con un $15 \%$, y ya en el estado C y D hay presencia de espermatozoides que ocupan un 35\% y de espermatocistos vacíos conun $12,5 \%$ (Fig. 9 b). Los promedios de cada proporción de los estados espermatogénicos no son significativamente diferentes entre los estados de madurez macroscópicos $(\mathrm{P}=0,10)$.

\section{ANATOMÍA REPRODUCTIVA DE LAS HEMBRAS}

\section{A. nigra y C. nigrum}

En el estado A o inmaduro, en algunos casos los ejemplares no presentaron gónada observable, en otros se observó sólo el ovario con ovocitos de tamaños de 0,5 a $1 \mathrm{~cm}$ de diámetro para ambas especies y en otros ejemplares se distinguió ovario y oviductos, con un ovario granulado, blanquecino y de forma tubular y de tamaño de 2,1 $\pm 0,21 \mathrm{~cm}$ en $A$. nigra y de 2,6 $\pm 0,14 \mathrm{~cm}$ en C. nigrum. Los oviductos son delgados y se expanden dando origen al útero que es delgado y de una longitud de $7 \pm 0,5 \mathrm{~cm}$ en $A$. nigra y de $6,5 \pm 0,34 \mathrm{~cm}$ en C. nigrum, y está totalmente unido a la parte superior de la cavidad abdominal.
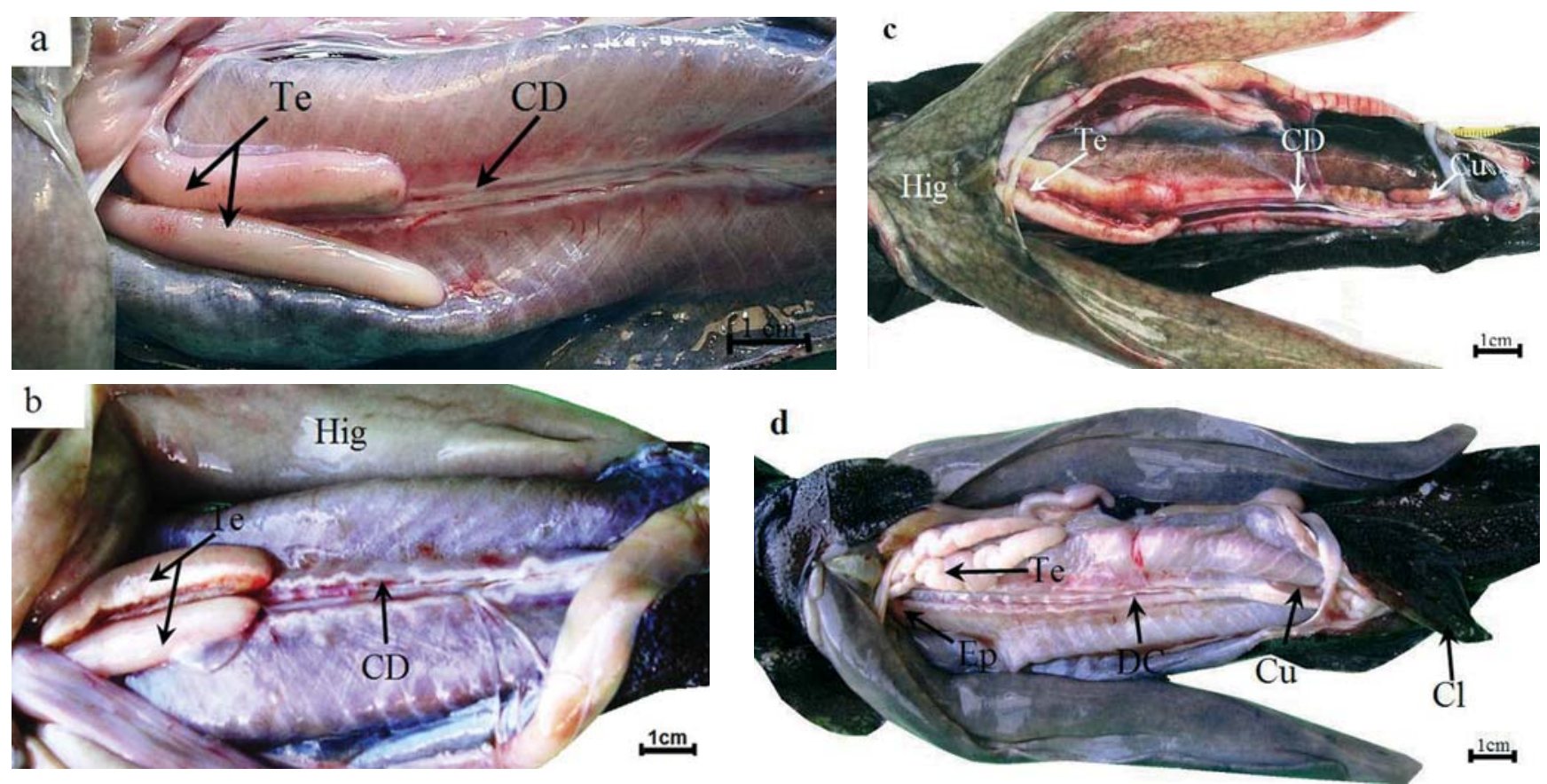

Figura 7. Aparato reproductivo de los machos de A.nigra (a) en estado B o en maduración, (b) en estado C o maduro y C. nigrum (c) en estado A o inmaduro, (d) en estado C o maduro. CL, Clasper; CD, Conductos deferentes; Cu, Conducto urinario; Ep, Epidídimo; Hig, Hígado; Te, testículos.

Figure 7. Male reproductive tract of A. nigra (a) in stage $\mathrm{B}$ or maturation, (b) in stage $\mathrm{C}$ or mature, and C. nigrum (c) in stage A or immature, (d) in stage $\mathrm{C}$ or mature. $\mathrm{Cl}$, Clasper, CD, Ducts deferens, $\mathrm{Cu}$, Duct urinary, Ep, Epididymides, Hig, Liver, Te, testis. 

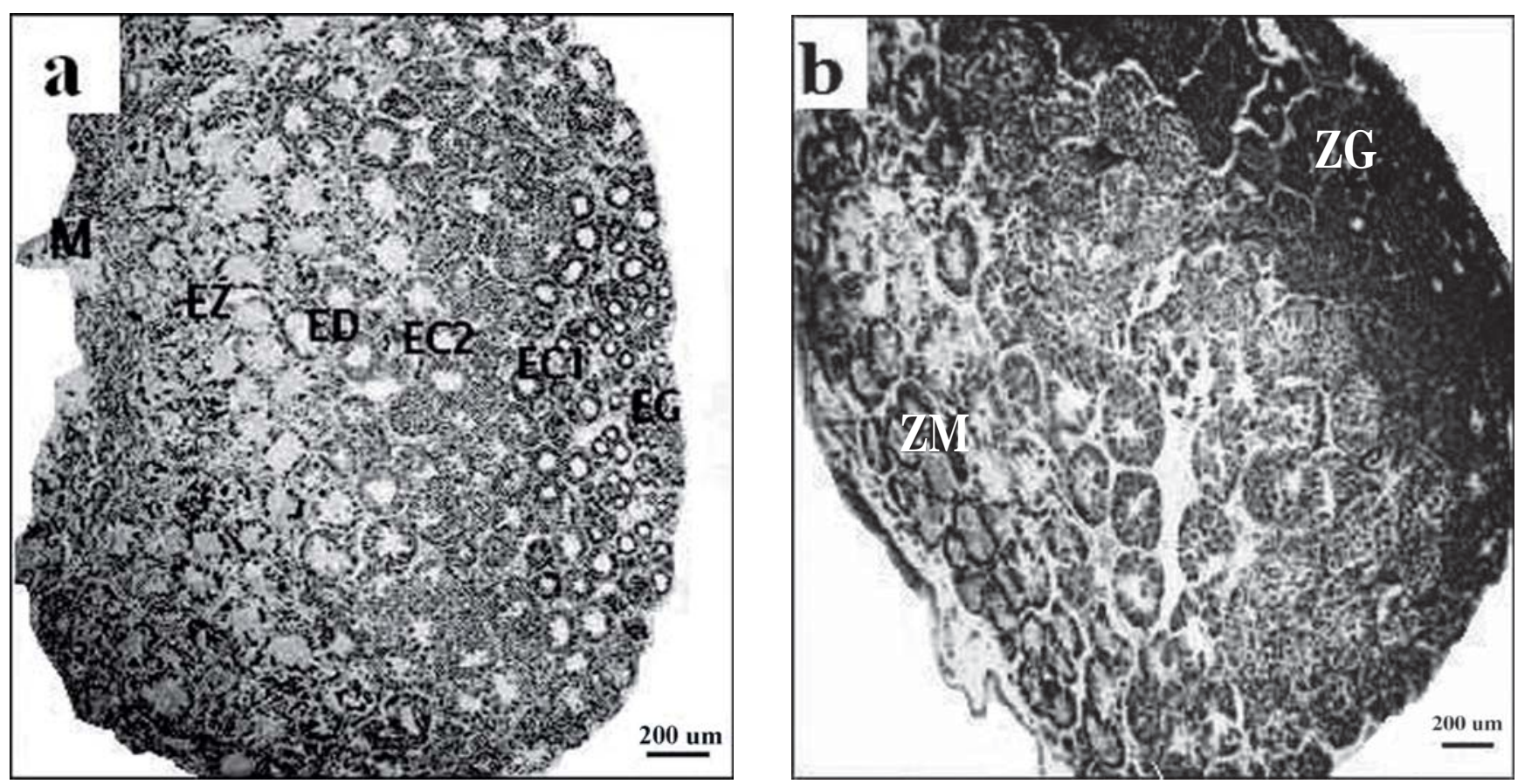

Figura 8. Corte transversal del testículo de $A$. nigra en estado D o activo (a) y C. nigrum en estado C o maduro (b). EC1, Espermatocitos primarios; EC2, Espermatocitos secundarios; ED, Espermátidas; EG, Espermatogonias; EZ, Espermatozoides; M, Mesorchium; ZG, Zona germinativa; ZM, Zona en maduración.

Figure 8. Cross section of A. nigra active or D stage testis (a) and C. nigrum C or mature stage testis (b). EC1, Primary spermatocytes, EC2, Secondary spermatocytes, ED, Spermatids, EG, Spermatogonia; EZ, Sperm, M, Mesorchium, ZG, Germination Zone, ZM, Maturing Zone.

(a)

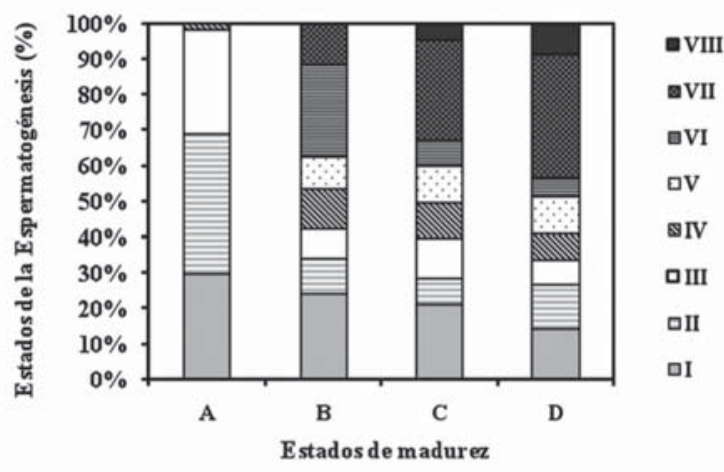

(b)

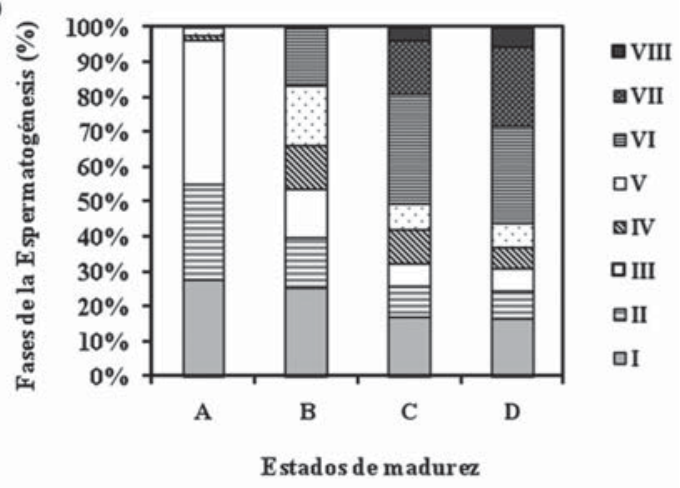

Figura 9. Proporción promedio de cada fase de la espermatogénesis definida en la Tabla 2, de cada estado de madurez macroscópico definido en Tabla 1. (a) A. nigra, (b) C. nigrum.

FigURE 9. Average proportion of each spermatogenesis stage defined in Table 2, of each stage of macroscopic maturity defined in Table 1. (a) A. nigra, (b) C. nigrum. 
En el estado $\mathrm{B}$ o en maduración el ovario está más diferenciado, con forma redondeada y ovocitos de diferentes tamaños, desde 0,3 a 1,5 cm, en ambas especies. El útero está desprendido de la parte superior de la cavidad abdominal y presenta un largo de 9,8 $\pm 0,11 \mathrm{~cm}$ en $A$. nigra y $10 \pm 0,02$ $\mathrm{cm}$ en $C$. nigrum, y su ancho es de $1,6 \pm 0,4 \mathrm{~cm}$ en $A$. nigra (Fig. 10a) y de $1,5 \pm 0,5 \mathrm{~cm}$ en $C$. nigrum.

En el estado C o maduro el ovario es redondo con ovocitos de $2 \mathrm{~cm}$ de diámetro, presentes en dos corridas que difieren en número en cada ovario en algunos ejemplares. En $A$. nigra en la parte derecha del ovario se observó un promedio de $8 \pm 2$ ovocitos, y en la izquierda un promedio de $7 \pm 2,6$ ovocitos. En C. nigrum en la parte derecha del ovario se observó un promedio de $6 \pm 2$ ovocitos y en la izquierda un promedio de $5 \pm 1$ ovocitos. El oviducto es delgado y fácilmente diferenciable del útero que ha adquirido un ancho de 2,3 $\pm 0,3$ cm en $A$. nigra (Fig. 10b) y de 2,4 $\pm 0,23 \mathrm{~cm}$ en $C$. nigrum.

En el estado D o en desarrollo el ovario es granulado, blanquecino y de aspecto acuoso y el útero está completamente lleno de vitelo de coloración amarilla y tiene un ancho de 3,2 $\pm 0,3 \mathrm{~cm}$ en $A$. nigra y de 3,0 $\pm 0,2 \mathrm{~cm}$ en $C$. nigrum y un largo de $11 \pm 0,3 \mathrm{~cm}$ en $A$. nigra y de 10,5 $\pm 0,2 \mathrm{~cm}$ en $C$. nigrum (Fig. 10c).

En el estado E o en diferenciación, el ovario es granulado con ovocitos que van desde los 0,3 a $1,5 \mathrm{~cm}$ de diámetro, ancho y de coloración blanquecina (Fig. 10d). En el útero se observan los embriones con su respectivo saco vitelino.

En el estado F o preparto el ovario es redondeado con ovocitos de consistencia firme de tamaños desde los 0,3 a $1,5 \mathrm{~cm}$ y el útero aumentó su ancho a $8 \mathrm{~cm} \pm 0,6$ en $A$. nigra y de 8,3 $\mathrm{cm} \pm 0,3$ en $C$. nigrum (Fig. 10e), debido a la presencia de embriones que ya han consumido completamente el vitelo de su saco vitelino y están completamente desarrollados, prontos a ser liberados al medio a través de la cloaca.
En el estado G o postparto el ovario se observa con forma granulada de consistencia firme y abarca mayor espacio en la cavidad abdominal, continúa el desarrollo de los ovocitos y el útero tiene un ancho de 3 a $3,8 \mathrm{~cm}$, debido a que ya se liberó a los embriones (Fig. 10f).

ESTRUCTURA INTERNA DEL OVARIO

En las dos especies de tiburones estudiados las hembras presentan la misma disposición de los ovocitos en el ovario, ubicándose en un borde de la gónada y son del tipo externo o carcharhínido (Fig. 11), y en el corte transversal se puede observar el órgano epigonal que mantiene sujeto al ovario. Cada ovocito está rodeado de tejido conjuntivo. Se pudieron observar tres tipos de ovocitos: previtelogénicos, de menor tamaño, vitelogénicos, los que presentaron una condición eosinófila que permitió distinguir que estaban completamente llenos de vitelo en su interior, y maduros, de mayor tamaño también completamente llenos de vitelo.

\section{TIPOS DE OVOCITOS}

\section{A. nigra}

En el estado de madurez macroscópico A se observaron ovocitos previtelogénicos de un tamaño de $50 \mu \mathrm{m}$ hasta de $200 \mu \mathrm{m}$, ubicados en la periferia de la gónada. En estado B se observaron ovocitos vitelogénicos de un tamaño de 800 a $1200 \mu \mathrm{m}$ y ubicados en una zona más central de la gónada. En estado C, los ovocitos están maduros y variaron en tallas de 1400 a $2500 \mu \mathrm{m}$, y en algunos casos un solo ovocito ocupaba la totalidad del corte del ovario.

\section{C. nigrum}

En estado de madurez macroscópico B se encontraron ovocitos vitelogénicos de un tamaño de 1000 a $1600 \mu \mathrm{m}$, de forma ovalada. En el estado de madurez macroscópico D y F, ambos con el ovario maduro, se encontró ovocitos maduros de un tamaño de 800 a $2300 \mu \mathrm{m}$, los cuales se ubicaron en la zona central de éste. 

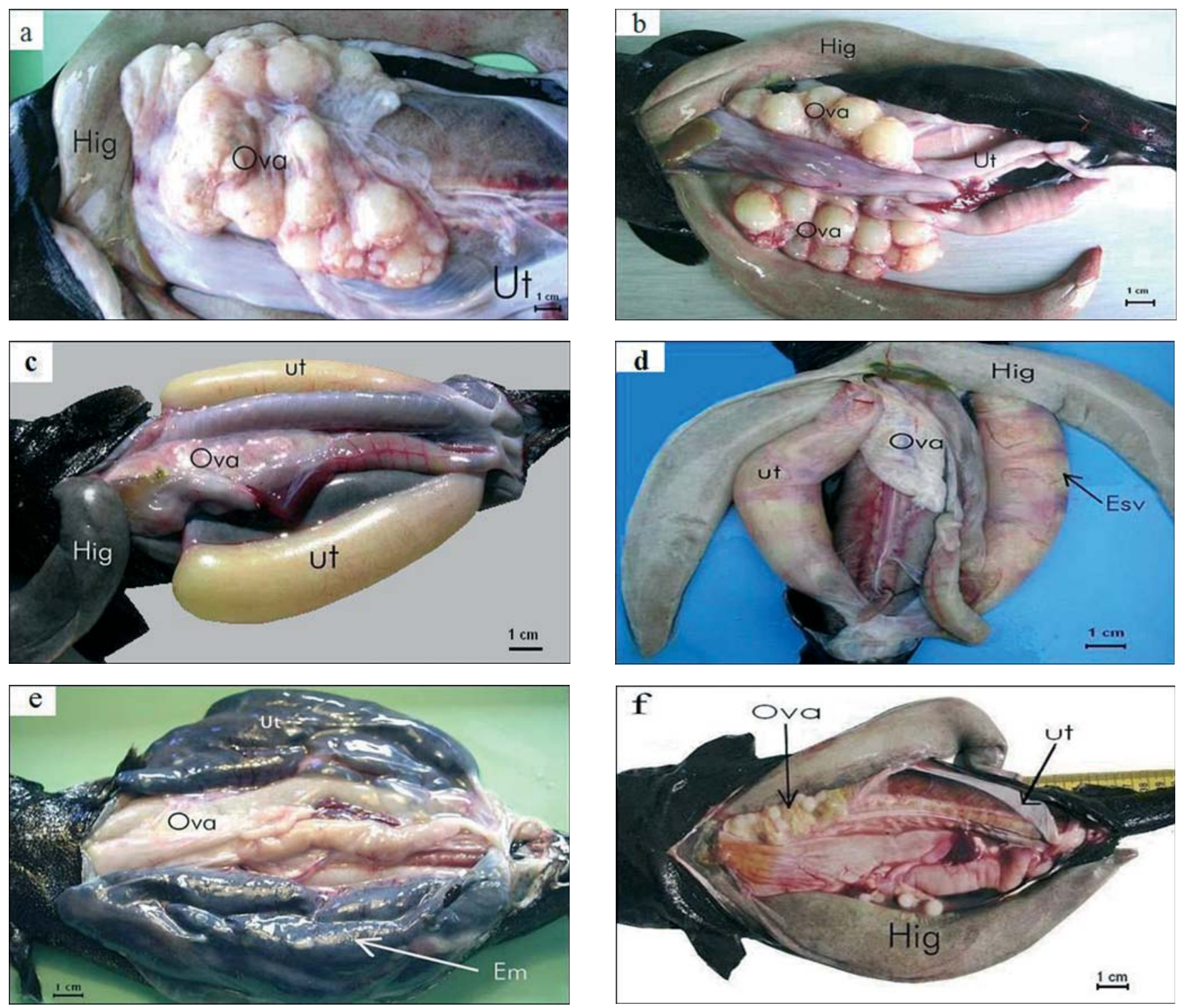

Figura 10. Aparato reproductivo de las hembras de A. nigra (a) en estado B o en maduración, (b) en estado C o madura, y de C. nigrum (c) en estado D o en desarrollo, (d) en estado E o en diferenciación, (e) en estado F o preparto y (f) en estado G o postparto. Esv, Embriones con saco vitelino; Em, Embriones; Hig, hígado; Ova, Ovario; Ut, Útero.

Figure 10. Female reproductive tract of $A$. nigra (a) in stage B or maturation, (b) C or mature stage, and C. nigrum (c) in stage D or developing, (d) in stage E or differentiation, (e) in stage F or pre-partum and (f) in stage G or post-partum. Esv, Embryos with yolk sac; Em, Embryos, Hig, Liver; Ova, Ovary, Ut, uterus. 

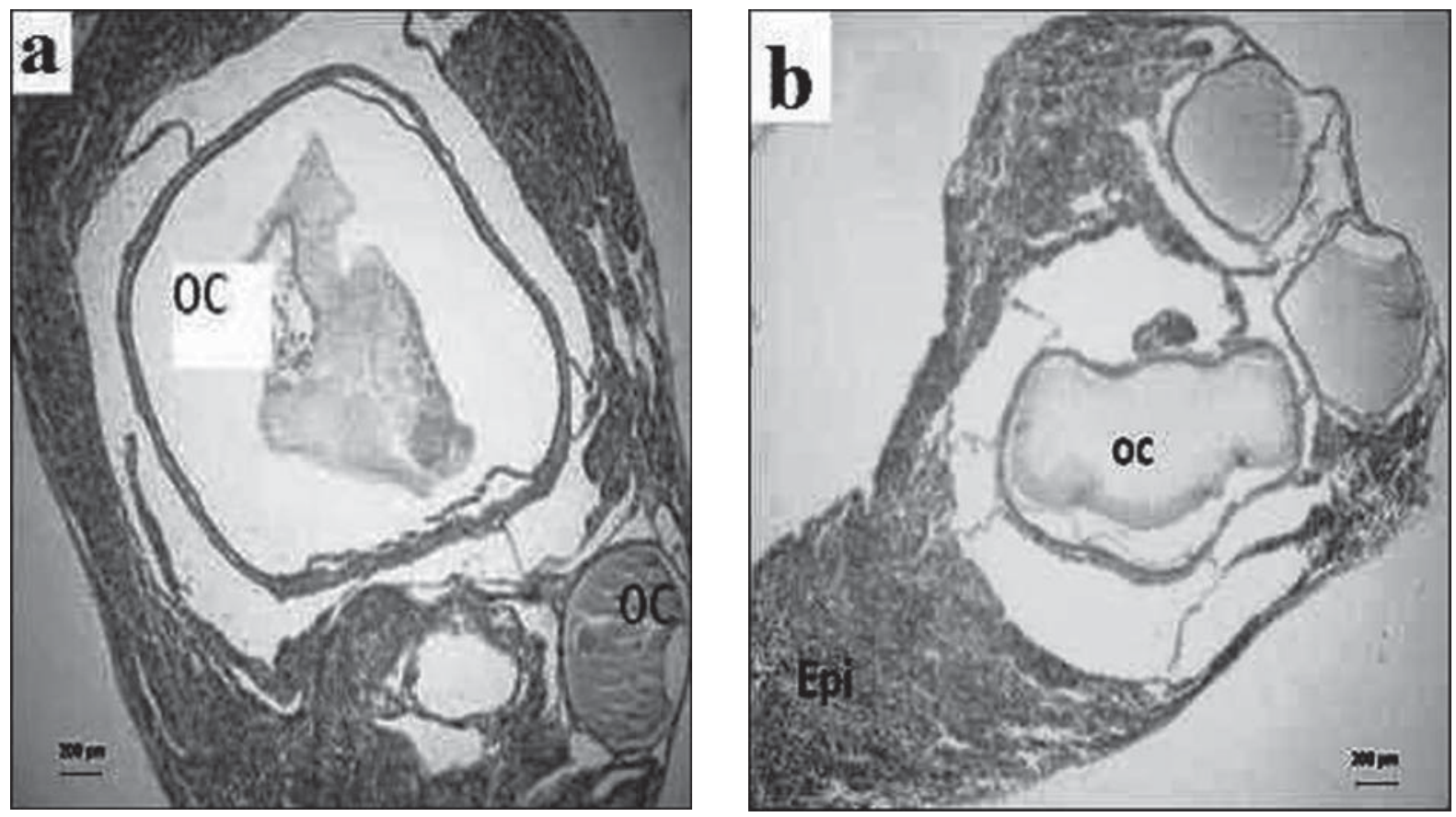

Figura 11. Ovario de A. nigra (a) en estado D o en desarrollo y C. nigrum (b) en estado C o maduro. Epi; Órgano epigonal; OC; ovocito.

Figure 11. Ovary of A. nigra (a) in stage D or developing stage, and C. nigrum (b) in stage C or mature stage. Epi; Epigonal Organ, OC, oocyte.

\section{DISCUSIÓN}

En ambas especies de tiburones estudiadas ocurre dimorfismo sexual en la longitud total, siendo las hembras más grandes que los machos, lo que es común en los elasmobranquios (Watson \& Smale 1998; Mabragaña \& Cosseau 2004; Rubio et al. 2005). Las tallas de primera madurez sexual de $A$. nigra obtenidas en este trabajo, de $38 \mathrm{~cm}$ LT para los machos y $39 \mathrm{~cm}$ LT en las hembras, son menores que las reportadas por Compagno (1984), que señala que en los machos ocurre a los $42 \mathrm{~cm}$ LT y en hembras a los $50 \mathrm{~cm}$ LT, más aún a partir de los $41 \mathrm{~cm}$ de LT se encontró hembras preñadas.

En $C$. nigrum la talla de madurez sexual estimada para ambos sexos (32 cm LT) es menor que la reportada por Lamilla y Bustamante (2005), donde se señala $35 \mathrm{~cm}$ de LT como la talla de madurez sexual. Por otra parte, Rubio et al. (2005) encontraron una hembra de $33 \mathrm{~cm}$ LT que definieron como en estado adulto, aseveración que se confirma en este trabajo, puesto que según el examen macroscópico las hembras se encontraban maduras a partir de los $31 \mathrm{~cm} \mathrm{LT}$, e incluso tenían embriones en el útero.
La relación entre la talla de la hembra y número de embriones es positiva en ambas especies de este estudio, lo que coincide con lo reportado para varios tiburones (Conrath 2004), aunque en otros tiburones de profundidad como por ejemplo Centrophorus squamosus no hay correlación entre la talla de la hembra y el número de embriones (Severino et al. 2009).

En los tiburones estudiados se presentó una fecundidad mayor en A. nigra (5-19 embriones) que en C. nigrum (415 embriones), aunque ambas son mayores a las reportadas en otros tiburones de profundidad como Centrophorus squamosus que tiene de 2 a 10 embriones (Severino et al. 2009) y en Centrocymnus crepidater, de 1 a 9 embriones (Nolan \& Hogan 2003).

Los embriones de ambas especies analizadas presentaron tallas de nacimiento similares, en torno a 16 y $14 \mathrm{~cm} \mathrm{LT}$, respectivamente. Estas tallas de nacimiento, al igual que lo observado en el tiburón vivíparo Squalus megalops que nace entre los 21 y 22 cm LT (Watson \& Smale 1998), 
son mayores que las determinadas en tiburones ovíparos como el pintarroja común, Schroederichthys chilensis (aproximadamente de $8 \mathrm{~cm} \mathrm{LT}$, Hernández et al. (2005)) y Scyliorhinus retifer (aproximadamente de 7,5 cm LT, Castro et al. (1988)), lo que representa una mayor inversión parental que aumenta su supervivencia al nacer.

Las hembras de las especies $A$. nigra y $C$. nigrum presentaron la misma morfología en los estados de madurez macroscópicos, ya que se pudo corroborar que son vivíparas lecitotróficas, al igual que muchos tiburones de profundidad (Nolan \& Hogan 2003; McLaughlin \& Morrissey 2005). Esto quiere decir que todos los nutrientes que el embrión necesita son producidos por la hembra, siendo el vitelo de los ovocitos el único recurso de nutrición embrionaria (Braccini et al. 2006), lo que constituye una ventaja para las crías y aumenta su supervivencia (Dulvy \& Reynolds 1997, Wourms 1993). Ambas especies presentan ovocitos de tamaño similar, los que continúan su desarrollo después de la gestación, y tienen el mismo tipo de ovario, externo o carcharhínido, según su estructura interna. Este tipo de ovario ha sido descrito para otros tiburones de profundidad como Centrophorus granulosus, Squalus acanthias, Scyliorhinus canicula y S. retifer (Pratt 1988). Estos antecedentes permiten generalizar que todas las especies de tiburones de profundidad pertenecientes al orden Squaliformes en los que se han realizado estudios reproductivos presentan el mismo tipo de ovario, aunque éste también se ha encontrado en tiburones pelágicos del orden Carcharhiniformes como Prionace glauca (Pratt 1979; Acuña et al. 2001).

La morfología testicular a nivel macróscopico de los tiburones $A$. nigra y C. nigrum en el estado A y B se presenta de la misma forma alargada y tubular, sin embargo en el estado $\mathrm{C}$ y $\mathrm{D}$ en $C$. nigrum la gónada adquiere una forma lobulada y enroscada, en cambio en $A$. nigra se mantiene la misma forma de los estados anteriores, sólo aumentando su tamaño. Estas características externas son importantes, junto con la forma que adquieren los demás componentes del sistema reproductivo, pero deben ser contrastadas histológicamente, ya que según Demski (1990) los exámenes de las condiciones reproductivas en el análisis de cortes histológicos de gónada son exactos para determinar la madurez gonádica de un organismo.

En el análisis microscópico de los machos de ambas especies de tiburones examinados, las gónadas en estado inmaduro no presentan espermatozoides en su estructura interna y el estado más avanzado de espermatogénesis que se detecta es espermátidas en estado 2, pero en muy bajo porcentaje. Sin embargo, Girard et al. (2000) encontraron espermatozoides en la estructura interna de la gónada en ejemplares inmaduros de Centroscymnus squamosus.
En el análisis microscópico de las gónadas de $A$. nigra en estado B se encontraron espermatozoides, lo que indica que el proceso de maduración es más avanzado y temprano en esta especie respecto de C. nigrum, en la cual en este estado sólo se encuentran espermátidas como la fase más avanzada de la espermatogénesis. En los estados C y D, según las características microscópicas, se presenta la mayor proporción de la gónada ocupada por espermatozoides, encontrándose un mayor porcentaje de ámpulas o folículos vacíos en el estado $\mathrm{D}$, por la liberación del esperma.

La estructura interna del testículo en ambas especies es definida como tipo diamétrico, lo que coincide con lo descrito para otros tiburones de profundidad como Centroscymnus coelolepis y Centrophorus squamosus (Girard et al. 2000), Squalus acanthias, Scyliorhinus canicula y S. retifer (Pratt 1988). Estos antecedentes permiten generalizar que todas las especies de tiburones de profundidad, que pertenecen al orden Squaliformes, en los que se han realizado estudios reproductivos, presentan testículos de este tipo.

Los valores máximos del IGS obtenidos en este trabajo en A. nigra coinciden temporalmente en machos y hembras, lo que sugiere que en ese período se encuentran preparados para reproducirse. Además el IHS es bajo en ese período, probablemente por un mayor uso de las reservas lipídicas, para producción de esperma en los machos y ovocitos en las hembras. En el caso de C. nigrum, el IGS es mayor en el mes en que hay mas aumento de hembras preñadas y previamente el IHS es mayor, lo que sugiere que en los meses anteriores a su periodo de reproducción acumulan reservas para el momento de mayor gasto energético. Lucifora (2003) ha descrito que las hembras poseen hígados grandes por demanda energética de la vitelogénesis, maduración de ovocitos y provisión de ovocitos para la alimentación de los embriones durante la gestación. En los machos de C. nigrum ocurrió una situación diferente a la de los de A. nigra, puesto que no muestran grandes fluctuaciones en los valores de IGS durante los meses de estudio, no detectándose una época reproductiva clara. Sin embargo, el IHS muestra un valor máximo marcado en los meses de junio y julio, y valores bajos en los meses siguientes, lo que puede significar que en los primeros la especie estaría en su fase reproductiva y en los siguientes se expresa el uso de las reservas lipídicas.

Wourms (1977) establece tres tipos básicos de ciclo reproductivo en los tiburones: los que se reproducen durante todo el año, los que cuentan con un ciclo anual parcialmente definido con uno o dos temporadas marcadas y los que tienen un ciclo anual o bianual bien definido. En el caso de los tiburones A. nigra y $C$. nigrum es necesario continuar con el estudio reproductivo por uno o dos años para establecer correcta y completamente las características de sus ciclos reproductivos, ya que nuestros resultados sólo representan 
a una fracción de dicho periodo. Asimismo, dada la gran extensión del área de estudio resulta de interés considerar establecer las potenciales variaciones latitudinales de dichos ciclos reproductivos.

\section{AGRADECIMIENTOS}

Se agradece a los grupos de Pesquerías e Histología de la Universidad Católica del Norte por el apoyo en la preparación y análisis de las muestras. Se agradece a Amanda Mondaca y Esteban Mondaca por su apoyo en el desarrollo de este estudio y además los generosos comentarios de los evaluadores, que contribuyeron a mejorar sustancialmente este trabajo.

\section{BIBLIOGRAFÍA}

Acuña, E., Cid, L., Pérez, E., Kong, I., Araya, M., Lamilla, J. \& Peñailillo, J. 2001. Estudio biológico de tiburones (marrajo dentudo, azulejo y tiburón sardinero) en la zona norte y central de Chile. Informes Técnicos FIP. FIP/IT N ${ }^{o}$ 2000- 23, 128 pp.

Acuña, E., Villarroel, J.C., Andrade, M. \& Cortés, A. 2005. Fauna acompañante en pesquerías de arrastre de crustáceos de Chile: Implicancias y desafíos desde la perspectiva de la biodiversidad. p. 395-425. En: Biodiversidad marina: Valoración, usos y perspectivas ¿Hacia dónde va Chile? Figueroa, E. (Ed.) Primera edición. Editorial Universitaria, Santiago de Chile.

Acuña, E., Alarcón, R., Arancibia, H., Cid, L., Cortés, A., Cubillos, L. \& León, R. 2007a. Evaluación directa de langostino colorado y langostino amarillo entre la II y VIII Regiones, año 2006. Informes Técnicos FIP". FIP/IT N ${ }^{\circ}$ 2006-04, 424 pp.

Acuña, E., Villarroel, J. C., Cortés, A., Alarcón, R., Cid, L., Arancibia, H., León, R., Cubillos, L., Bahamonde, R., Canales, C., Montenegro, C., Leiva B. \& Contreras, F. 2007b. Evaluación directa de camarón nailon entre la II y VIII Regiones, año 2006. Informes Técnicos FIP. FIP/IT $\mathrm{N}^{\mathrm{o}} 2006-11,275 \mathrm{pp}$.

Barone, M., De Ranieri, S., Fabiani, O., Pirone, A. \& Serena, F. 2007. Gametogenesis and maturity stages scale Raja asterias Delaroche, 1809 (Chondrichthyes, Rajidae) from the south ligurian seal. Hydrobiologia 580: 245- 254.

Braccini, J. M., Hamlett, W. C., Gillanders, B. M. \& Walker, T. L. 2006. Embryo development and maternal - embryo nutritional relationships of piked spurdog (Squalus megalops). Marine Biology 150: 727- 737.

Castro, J., Bubucis, P.M. \& Overstrom, N.A. 1988. The reproductive biology of the Chain Dogfish, Scyliorhinus retifer. Copeia 1988 (3):740-746.

Compagno, L. 1984. An annotated and illustrated catalogue of shark species known to date. Sharks of the world. Part 1 Hexanchiformes to Lamniformes. FAO Fisheries Synopsis $\mathrm{N}^{\circ}$ 125. Vol. 4, 249 pp.

Conrath, C. L. 2004. Reproductive biology. P. 133-164. In:
Elasmobranch fisheries Management Techniques. Musick, J. A. \& R. Bonfil (Eds.). APEC Secretariat. 337 pp.

DemSKI, L. 1990. Elasmobranch reproductive biology: implications for captive breeding. Journal of Aquariculture \& Aquatic Sciences 5(4):84-95.

Dulvy, N. K. \& Reynolds, J. D. 1997. Evolutionary transitions among: egg-laying, live-bearing and maternal inputs in sharks and rays. Proceedings of the Royal Society of London B 264:1309-1315.

Girard, M., Rivalan, P. \& Sinquin, G. 2000. Testis and sperm morphology in two deep-water squaloid sharks, Centroscymnus coelolepis and Centrophorus squamosus. Journal of Fish Biology 57:1575-1589.

Hernández, S., Lamilla, J., Dupré, E. \& Stotz, W. 2005. Desarrollo embrionario de la pintarroja común Schroederichthys chilensis (Guichenot, 1848) (Chondrichthyes: Scyliorhinidae). Gayana 69(1):191-197.

Kyne, P. \& SimpFEndorfer, C. 2007. A collation and summarization of available data on deepwater chondrichthyans: Biodiversity, life history and fisheries. IUCN SSC Shark Specialist Group for the Marine Conservation Biology Institute. $137 \mathrm{pp}$.

Lamilla, J. \& Bustamante, C. 2005. Guía para el reconocimiento de tiburones, rayas y quimeras de Chile. Oceana 17:1-80.

Large, P.A. \& Bergstad, O.A. 2003. Deepwater fish resources in the northeast Atlantic: Fisheries, state of knowledge on biology and ecology and recent developments in stock assessment and management.149-161pp. En: Deep sea 2003: Conference on the governance and management of deep-sea fisheries. Part 1 Conference report. Shotton, Roos (Ed). FAO Fisheries Proceedings. 718 pp.

LuCIFORA, L. O. 2003. Ecología y conservación de los grandes tiburones costeros de bahía Anegada, Provincia de Buenos Aires, Argentina, Tesis doctoral. U. Nacional de Mar del Plata, Facultad de Ciencias Exactas y Naturales, Instituto Nacional de Investigación y Desarrollo Pesquero, Mar del Plata, $401 \mathrm{pp}$.

Mabragaña, E. \& Cosseau, M. B. 2004. Reproductive biology of two sympatric skates in the south-west Atlantic: Psammobatis rudis and Psammobatis normani. Journal of Fish Biology 65: 559- 573.

Maruska, K.P., Cowie, E.G. \& Tricas, T.C. 1996. Periodic Gonadal Activity and Protracted Mating in Elasmobranch Fishes. The Journal Experimental Zoology 303A: 577-589.

McLaughlin, D. M. \& Morrissey, J. F. 2005. Reproductive biology of Centrophorus cf. uyato from the Cayman Trench, Jamaica. Journal Marine Biological Association. UK. 85, 5027/1-8.

Moreno, I., Acevedo, K., Grijalba-Bendeck, M., Acero, A. \& PARAmo, J. 2010. Reproducción de la raya eléctrica Narcine bancrofti (Torpediniformes: Narcinidae) en Santa Marta, Caribe Colombiano. Latin American Journal of Aquatic Research 38:27-36.

Nolan, C. P. \& Hogan, F. 2003. A note on the reproductive biology of the longnose velvet dogfish (Centroscymnus crepidater) From the Northeast Atlantic. 85-86 pp. En: Deep Sea 2003: Conference on the governance and management of deep-sea fisheries. Part 2 Conference poster papers and workshop papers. Shotton, Roos (Ed). FAO Fisheries 
Proceedings. $487 \mathrm{pp}$.

Pratt, H.L. 1979. Reproduction in the blue shark, Prionace glauca. Fishery Bulletin 77(2): 445-469.

Pratt, H.L. 1988. Elasmobranch Gonad Structure: A description and survey. Copeia 1988 (3): 719-729.

Rubio, E., Pedraza, M. \& Zapata, L. 2005. Primer registro del tiburón perro Centroscyllium nigrum (Chondrichthyes: Squalidae) en aguas del Pacífico colombiano. Gayana 69(1):113-117.

Sielfeld, W. \& Vargas, M. 1996. Composición y Estructura de la ictiofauna demersal en la zona norte de Chile. Investigaciones Marinas, Valparaíso, 24:3-17.

Stehmann, M.F. 2002. Proposal of a maturity stages scale for oviparous and viviparous cartilaginous fishes (Pisces, Chondrichthyes). Archive Fishery Marine Research 50(1): 23-48.

Tresierra, A. E., Culquichicon, Z. G. \& Veneros, B. 2002. Biología Reproductiva en peces. Primera Edición. Editora Nuevo Norte, Perú, 286 pp.

Watson, G. \& Smale, M.J. 1998. Reproductive biology of shortnose spiny dogfish, Squalus megalops, from the Agulhas bank, South Africa. Marine Freshwater Research 49:695-703.

Wourms, J. 1977. Reproduction and Development in Chondrichthyan Fishes. American Zoologist 17:379-410.

Wourms, J. 1993. Maximization of evolutionary trends of placental viviparity in the spadenose shark, Scoliodon laticaudus. Environmental Biology Fishery 38(1-3): 269-294.

Recibido: 08.06.10

Aceptado: 21.03.11 